\title{
Mesiodens: A Case Report and Literature Review
}

\author{
Akhil Jose E J*, PrashantBabaji and Shashibushan k \\ Department of Pedodontics and Preventive dentistry, Sharavathi Dental College and Hospital, India
}

Received: 非 April 14, 2018; Published: 畊 April 27, 2018

*Corresponding author: Akhil Jose EJ, Department of Pedodontics and Preventive dentistry, Sharavathi Dental College and Hospital, Shimoga, Karnataka, India

\begin{abstract}
Supernumerary teeth are considered to be one of the most significant dental anomalies affecting the primary and early mixed dentition and may cause a variety of pathological disturbances to the developing permanent dentition and also resulting in poor dental and facial esthetics. Mesiodens are the erupted or unerupted extra tooth in the midline of maxilla, along with normal teeth (between the central incisors). Early diagnosis and prompt treatment are necessary for prevention of deleterious effects of mesiodenson dentoalveolar structures. The aim of this case report is to share knowledge about management of mesiodens which might assist the clinician in decision-making.
\end{abstract}

KeyWords: Supernumerary Teeth; Mesiodens; Prevalence

\section{Introduction}

A supernumerary tooth is a developmental anomaly characterized by more number of teeth than normal series $[1,2]$. The prevalence varies between 0.3 and $3.8 \%$ of the population. This anomaly of unknown etiology [1]. Supernumerary teeth may occur as a single isolated anomaly or in association with specific developmental syndromes like cleft lip and palate, Downs syndromes, Cleidocranial dysplasia, chorhinophalangeal syndrome and Gardner's syndrome etc $[1,2]$. Supernumerary teeth in the maxillary anterior region may also compromise facial estheticsseries [2]. Mesiodens, most common supernumerary teeth accounts around $80 \%$ of all supernumerary teeth series which mayerupt normally, appear inverted, stay impacted or take a horizontal position series [1]. The shape may be tuberculate, conical, odontome, or closely resemble the normal tooth, based on their morphologyseries [2]. Mesiodens can occur individually or as multiples called as mesiodentes [3].

The etiology of these teeth is still obscure although several theories have been suggested such as genetics, dichotomy of the tooth bud, hyperactivity of the dental lamina, and a combination of genetic and environmental factors, proliferation of odontogenic cell rests, palatal off shoot from continued activity of the dental lamina after the normal number of tooth buds are formed, atavism and consanguineous marriages [1-7].
Mesiodens may give rise to a variety of complications such as delayed eruption, ectopic eruption of adjacent teeth, midline diastema, impaction, malalignment of incisors, displacement and axial rotation of adjacent teeth, radicular resorption of adjacent teeth, crowding, dilacerations, possible development of dentigerous cyst and migration into nasal cavity or maxillary sinus and fistula between oral and nasal cavity series $[1,2,8]$.

This case report describes an extremely rare occurrence of bilaterally impacted mesiodentes with an inverted mesiodens in the hard palate area with its associated anomalies. It also describes about early diagnosis with treatment planning.

\section{Case Report}

A 7 year old male patient came with a chief complaint of an extra tooth in upper front teeth region. Patient complaints of irritation from this tooth. There was no associated history of trauma and pain. Medical and family history was non-contributory. There were no signs of any syndrome. On intra oral examination it was observed that a mesiodens was present palatally between 11 and 21 (Figure 1). On IOPA radiograph examination showed the presence of mesiodens of conical shape parallel to the teeth between 11 and 21 (Figure 2). Blood investigations were done and 
the reports were well within normal limits. Treatment was planned to extract the mesiodens (Figure 3). Later IOPA radiograph was taken (Figure 4) to confirm the extracted mesiodens (Figure 5). The wound healing was uneventfully and the patient presented with no post-operative complications.

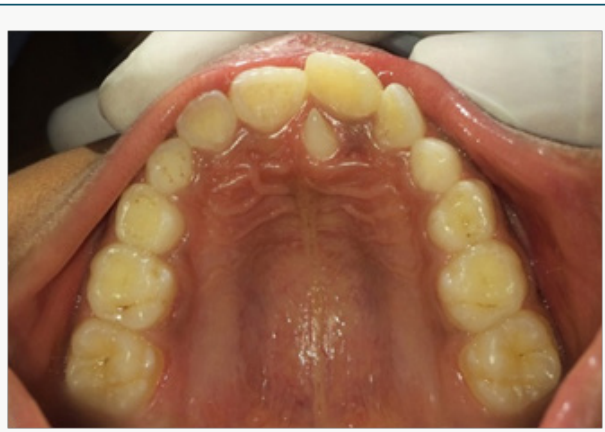

Figure 1: Intra-oral photograph showing mesiodens between 11 and 21.

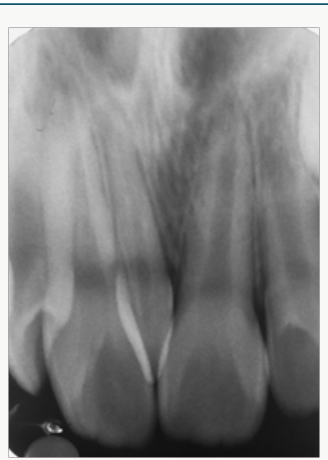

Figure 2: IOPA showing mesiodens between 11 and 21.

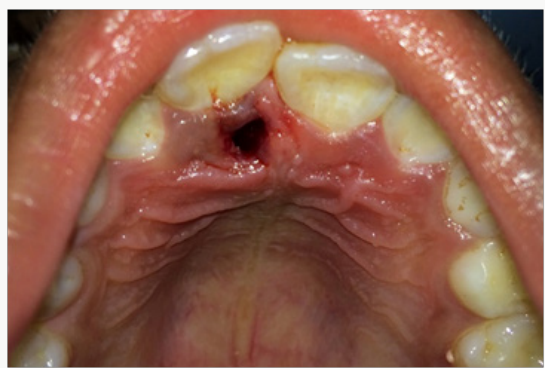

Figure 3: Intra-oral photograph showing socket site after extraction of mesiodens.

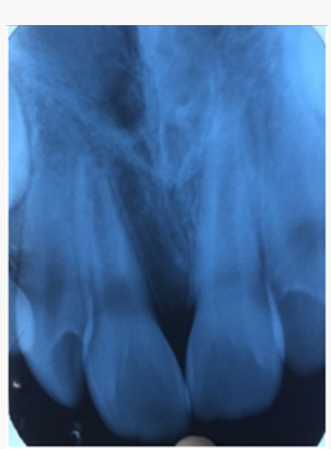

Figure 4: Post-operative IOPA after extraction of mesiodens.

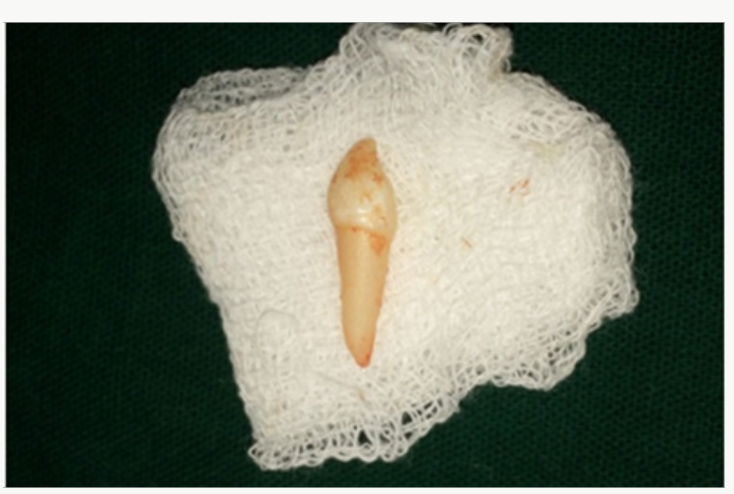

Figure 5: Extracted mesiodens.

\section{Discussion}

Mesiodens is considered as an extra tooth along with normal teeth with a prevalence 0.15 to $1.9 \%$. One mesiodens occurred in $78.1 \%$ of the cases and in two in $21.9 \%$ of the cases 1 . Most of the mesiodentes (55.2\%) were found to be in vertical position (55.2\%) followed by inverted position (37.6\%) and horizontal position (7\%) [6]. Most of the mesiodens remain unerupted, and if they are erupting, it will be an ectopic eruption $[1,6]$.

As maxillary permanent central incisors erupt 7 and 9 years of age, most of the mesiodens are reported at this age. Presence of mesiodens is mainly found during the radiological examination of nonerupted or axial rotated of upper central incisors or diastema [1]. Treatment of impacted mesiodens centers on several factors which include the age of the child, clinical manifestation, capacity of the child to tolerate the surgical procedure, root development stage of the adjacent permanent teeth etc [9]. If the mesiodensare asymptomatic then they are left in place and extraction is delayed until the adjacent teeth root completion $[2,10]$. Mesiodens are always under keen observational follow up. Their extraction is always discouraged due to the fear of iatrogenic damage to the permanent teeth or its vitality during extraction time [7,11]. Early surgical intervention in a young child requires treatment under general anesthesia. The associated complication risks and related psychological dental anxiety opposes the use of general anaesthesia $[2,12]$. Even if the supernumerary teeth remain in the jaw for years without any complications periodic recall checkups are needed due to its cystic complications(in about $4-9 \%$ cases) and a possibility of development of a carcinoma $[5,13]$.

As long as the coronal part of the follicle of the supernumerary teeth remains intact, migration of the supernumerary teeth is possible which may cause any disturbance in eruption or alignment of permanent dentition directs the extraction during mixed dentition $[6,7,14]$. However, in this present case, the mesiodens had already erupted into the oral cavity palatally causing irritation. It may cause midline diastema, malalignment, rotation of adjacent teeth structure and unesthetics. Due to these ongoing and future complications, the mesiodens was indicated for extraction. 
Nevertheless, extraction that has been done at the right time in this case, can prevent the future migration of the supernumerary teeth and associated complications. Fortunately, post-surgical phase was uneventful. On surgical removal of impacted supernumerary teeth in the maxillary anterior region, there are no much reports on complications or disturbances to adjacent teeth with incomplete root development compared to surgery postponed for complete root development of incisors [2].

Early intervention and surgical removal of the unerupted supernumerary tooth as soon as it is detected helps to prevent the future complications such as retarded eruption of the permanent incisors or the need for any additional surgical procedure. This intervention gives an advantage to the spontaneous eruptive potential of the permanent incisor, to avoid eruption delay or failure of their eruption, crowding, space loss and midline shift which may require extensive orthodontic therapy. Therefore, an impacted supernumerary tooth should be extracted as soon as diagnosed at a young age when it appears to cause damage to adjacent teeth $[2,9]$.

The spontaneous eruption of impacted maxillary incisors after removal of the supernumerary teeth depends on several factors such as the depth of the impacted tooth, amount of root development, the angulation of the impacted tooth, and the available space required for its eruption. Therefore, immediate orthodontic extrusive traction to erupt the impacted incisors following the surgical removal of the supernumerary teeth was highly recommended [15]. Thus avoid the need for a second surgery. Moreover, it has been suggested that early exposure and bonding the unerupted incisor may result in loss of supporting bone and create scar tissue, which may further delay its eruption [2].

\section{References}

1. Mukhopadhyay S (2011) Mesiodens: A clinical and radiographic study in children. J Indian SocPedodPrev Dent 29(1): 34-38.
2. Sarne O, Shapira Y, Blumer S, Finkelstein T, Schonberger S, et al. (2018) Supernumerary Teeth in the Maxillary Anterior Region: The Dilemma of Early Versus Late Surgical Intervention J ClinPediatr Dent 42(1): 55-61.

3. Viswanathan R, Pai S (2015) Bilateral impacted inverted mesiodentes in the palatal vault: A rare case report. Ped Dent J 25(1): 26-28.

4. Nagaveni NB, Umashankara KV, Reddy BP, Radhika NB, Satisha TS (2010) Multi-lobed mesiodens with a palatal talon cusp: A rare case report. Braz Dent J 21(4): 375-378.

5. Jindal R, Sharma S, Gupta K (2012) Clinical and surgical considerations for impacted mesiodens in young children: An update. Indian J Oral Sci 3(2): 94-98.

6. Desai VD, Baghla P, Sharma R, Gaurav I (2014) Inverted Impacted Mesiodents: A Case Series. J Adv Med Dent Scie 2(2): 135-140.

7. CanogluEbru, ErNuray, CehreliZafer C (2009) Double inverted mesiodentes: Report of an unusual case. Eur J Dent 3(3): 219-223.

8. Hasan S, Ahmed SA, Reddy LB (2014) Dentigerous cyst in association with impacted inverted mesiodens: Report of a rare case with a brief review of literature. Int J App Basic Med Res 4: 61-64.

9. Omer RS, Anthonappa RP, King NM (2010) Determination of the optimal time of surgical removal of unerupted anterior supernumerary teeth. Pediatr Dent 32(1): 14-20.

10. Rajab LD, Hamdan MA (2002) Supernumerary teeth: review of the literature and a survey of 152 cases. Int J Paediatr Dent 12(4): 244-254.

11. Garvey MT, Barry HJ, Blake M (1999) Supernumerary teeth An over view of classification, diagnosis and management. J Can Dent Assoc 65(11): 612616

12. Gupta S, Marwah N (2012) Impacted supernumerary teeth early or delayed intervention: decision making dilemma? Int J ClinPediatr Dent 5(3): 226-230.

13. Olson JW, Miller RL, Kushner GM, Vest TM (2000) Odontogenic carcinoma occurring in a dentigerous cyst: Case report and clinical management. J Periodontol 71(8): 13651370

14. Hyun HK, Lee SJ, Lee SH (2009) Clinical characteristics and complications associated with mesiodentes. J Oral MaxillofacSurg 67(12): 2639-2643.

15. Ashkenazi M, Greenberg BP, Chodik G, Rakocz M (2007) Postoperative prognosis of unerupted teeth after removal of supernumerary teeth or odontomas. Am J OrthodDentofacOrthop 131(5): 614-619.

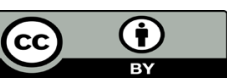

This work is licensed under Creative Commons Attribution 4.0 License

To Submit Your Article Click Here: Submit Artic

DOI: $10.32474 /$ IPDOAJ.2018.01.000113

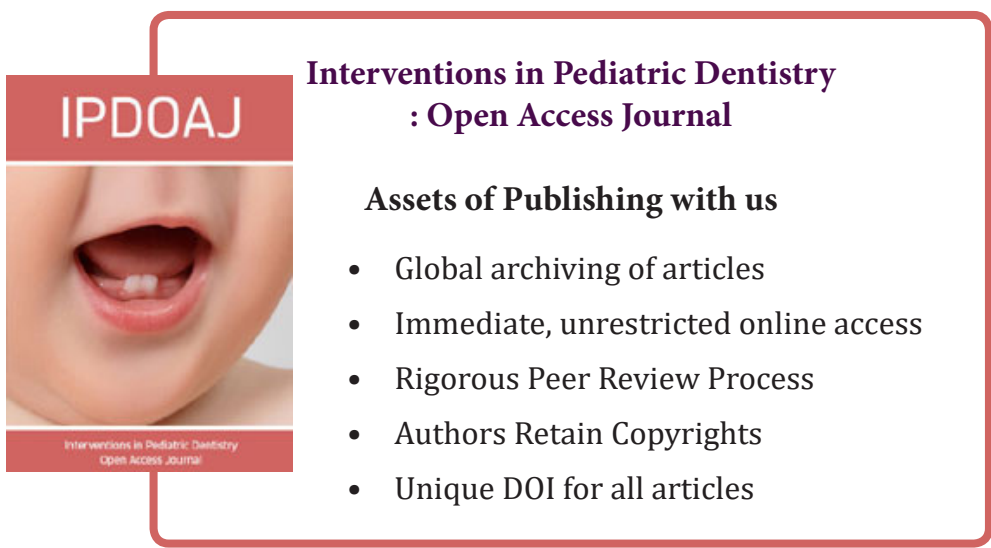

